University of Wollongong

Research Online

Faculty of Business - Papers (Archive)

Faculty of Business and Law

2013

Evidence on the convergence of per capita income: a comparison of founder members of the Association of South East Asian Nations and the South Asian Association of Regional Cooperation

Kankesu Jayanthakumaran

University of Wollongong, kankesu@uow.edu.au

Shao-Wei Lee

Taiwan Academy of Banking and Finance, shaoweil@uow.edu.au

Follow this and additional works at: https://ro.uow.edu.au/buspapers

Part of the Business Commons

Research Online is the open access institutional repository for the University of Wollongong. For further information contact the UOW Library: research-pubs@uow.edu.au 


\title{
Evidence on the convergence of per capita income: a comparison of founder members of the Association of South East Asian Nations and the South Asian Association of Regional Cooperation
}

\begin{abstract}
This paper investigates the per capita income convergence patterns of a set of Association of South East Asian Nations (ASEAN) and South Asian Association of Regional Cooperation (SAARC) countries. We obtained a time-series analysis for stochastic convergence by applying unit-root tests in the presence of two endogenously-determined structural breaks. We then supplemented the results by tests that produced evidence for $b$ convergence. The evidence shows that the relative per capita income series of ASEAN- 5 countries were consistent with stochastic convergence and $b$ convergence, but this was not found for SAARC- 5 countries. For the ASEAN-5 countries, the structural breaks associated with the world oil crisis and the Asian crisis impacted heavily on the convergence/divergence process.
\end{abstract}

\section{Keywords}

cooperation, east, south, capita, association, income, comparison, convergence, evidence, members, asian, nations, regional, per, founder

\section{Disciplines \\ Business}

\section{Publication Details}

Jayanthakumaran, K. \& Lee, S. (2013). Evidence on the convergence of per capita income: a comparison of founder members of the Association of South East Asian Nations and the South Asian Association of Regional Cooperation. Pacific Economic Review, 18 (1), 108-121. 


\title{
Evidence on the convergence of per capita income: a comparison of founder members of the Association of South East Asian Nations and the South Asian Association of Regional Cooperation
}

\author{
Kankesu Jayanthakumaran* University of Wollongong \\ Shao-Wei Lee Taiwan Academy of Banking and Finance
}

\begin{abstract}
This paper investigates the per capita income convergence patterns of a set of ASEAN and SAARC countries. We obtained a time-series analysis for stochastic convergence by applying unit-root tests in the presence of two endogenously determined structural breaks. We then supplemented the results by tests that produced evidence for $\beta$ convergence. The evidence shows that the relative per capita income series of ASEAN-5 countries were consistent with stochastic convergence and $\beta$ convergence, but this was not found for SAARC-5 countries. For the ASEAN-5 countries, the structural breaks associated with the world oil crisis and the Asian crisis impacted heavily on the convergence/divergence process.
\end{abstract}

JEL Codes: F15, I38, C22

\section{Introduction}

This paper documents and explains the income convergence experienced by the member countries of the Association of South East Asian Nations (ASEAN) and the South Asian Association of Regional Cooperation (SAARC) over the last two decades, following their attempts at regional integration. The ASEAN and SAARC nations have had different levels success in regards to integration. In the present paper, their regional trade agreements (RTAs) are discussed and the effectiveness of the regions' integration is compared in terms of convergence.

Considerable debate has occurred about the impact of regional trade and investment reforms on regional income inequality in emerging economies, mainly because they have traditional concerns about equality over efficiency. ${ }^{1}$ It is important to understand the channels that lead to income divergence at a regional level, and to correct or

\footnotetext{
* Address for Correspondence: School of Economics, University of Wollongong, Wollongong, NSW 2522, Australia. Email: Kankesu@uow.edu.au.

The authors would like to thank the anonymous referee of this journal and Professor Kenneth S. Chan for useful comments. The usual disclaimers apply.

1 Wagle (2007) focuses on the inequality of South Asian countries, and reveals declining inequality in more intensively liberalising economies such as Sri Lanka and Pakistan.
} 
minimise these divergences. This paper fills the research gap concerning the integration of ASEAN and SAARC nations.

Convergence hypothesis predicts that a nation's level of income will approach a steady state, depending on the characteristics of the given country. Incomes converge when both stochastic and $\beta$ convergence conditions prevail. The procedure begins by confirming the stochastic convergence and then applying $\beta$ convergence appropriately. The literature on endogenous growth applies the above premises to test the trade-income convergence/divergence nexus (Barrow and Sala-i-Martin, 1992; Ben-David, 1996; Slaughter, 1997; Ghose 2004; Dawson and Sen, 2007; Niebuhr and Schlitte, 2004). The endogenous growth model explores convergence in level, immediate and eventual convergence of growth rates. This exercise is useful if a large and persistent gap exists between the poor and rich (Leung and Quah, 1996; Quah, 1996).

The initial studies were cross-sectional and involved regressions of long-term growth rates on initial income levels and the independent variables of large samples of countries (Barrow and Sala-i-Martin, 1992). If heterogeneity exists across economies, the cross-sectional studies attract criticism. ${ }^{2}$ Therefore, a growing number of time series (Dawson and Sen, 2007) and panel studies (for example, Choi 2009) replace the cross-sectional studies. However, we should not ignore that the speed of convergence to a steady state varies between cross-countries studies, mainly due to heterogeneity in population growth, technical change or progressiveness of income taxes. The timeseries studies are missing the above ingredients, and are capable only of explaining an average growth rate of a nation's relative income. Romer (1994) criticises the empirical work on converging per capita income across countries and indicates that researchers should use all the available evidence — beyond the models — in order to overcome the convergence controversy. ${ }^{3}$

Income convergence is likely to occur with committed regional trade agreements (RTAs), which often have geographical and cultural links (Freund 2000), or by global integration (Silvestriadou and Balasubramanyam, 2000). Regional trade and

2 Critics of cross-sectional literature argues: First, that distributional dynamics of per capita incomes may rule out stochastic convergence, even though beta convergence results have been confirmed (Friedman, 1992). Second, a mean decline does not necessarily reflect any casual mechanism ensuring convergence; probability reveals that extreme outcomes will be adopted by average outcomes and extreme outcomes are unlikely to be repeated (Baddeley, 2006). Finally, those cross-sectional tests have problems identifying a group of countries that are converging (Linden, 2000).

3 Romer (1994) argues that the convergence controversy only captured part of what endogenous growth has spelt out, and is therefore misleading; and that the data constraints and unrealistic assumptions are important factors in the analytical framework that generates misleading results. 
investment reforms tend to allocate resources internally among member nations, in response to the elimination of quotas and tariffs in sectors that are traditionally protected. The per capita convergence that does occur is mainly due to people moving from low productivity activities to high productivity activities that have cost advantages. Latecomers can easily adopt the existing technologies that pioneers developed.

Niebuhr and Schlitte (2004) show that per capita incomes in the 15 European Union countries converged between 1950 and 2000 at an estimated average rate of approximately 1.6 per cent. Galvao and Reis Gomes (2007) show that 12 out of 19 Latin American countries converged, while Moon (2006) reports that East Asia tended to converge during the period 1980-2000. Li and $\mathrm{Xu}$ (2007) revealed significant effects of economic freedom on improving economic convergence in a panel of seven Asian economies; while Oh and Evans (2011) established evidence of convergence for the 15 advanced industrial countries. Fung and Chow (2011) conclude that the more productive airports in China are pushing the frontiers of technology faster by adopting new technology, and this is facilitating lower productive airports catching up.

The present research applied unit-root tests with two endogenously determined structural breaks (stochastic convergence), expecting that this measure would capture two possible causes that affect the convergence of per capita income over time. Market incentives and government policies may affect discovery, diffusion and technological advance, and may shape the dynamics of regional convergence. Macroeconomic fluctuations, such as business cycles, co-movement in subsets of countries, uncertainty in oil prices and increasing costs of international transportation may also shape regional inequality.

The remainder of this paper is structured as follows. Section 2 deals with trade liberalisation and regional income convergence in ASEAN-5 and SAARC-5 countries. Section 3 deals with methodology and Section 4 with the results. Section 5 presents the conclusions.

\section{Association of South East Asian Nations-5 and South Asian Association of Regional Cooperation-5 countries}

Malaysia, Indonesia, Thailand, the Philippines and Singapore formed the ASEAN-5 group in 1967 to promote cooperation in economic, social and cultural areas, and to 
promote regional peace and stability. ${ }^{4}$ Brunei joined ASEAN in 1984. Notable features in the region include a preferential trade agreement (PTA) in 1977 and unilateral economic reforms (deregulation, trade, finance, tax and foreign direct investment) following the severe recession of the 1980s. The ASEAN Free Trade Area (AFTA) was formed in 1992. A common effective preferential tariff (CEPT) agreement that limited tariffs to $0-5$ per cent by 2002-03 was signed directly after the formation of the ASEAN Free Trade Area (AFTA). In the 1990s an extension of AFTA to new members (i.e Burma, Cambodia, Laos and Vietnam) renewed interest in a broader ASEAN integration and commitment to open regionalism.

The 2007 The ASEAN Economic Community (AEC) Blueprint completed the plan to achieve AEC by the year 2015, from its original target of 2020. The blueprint incorporates a complete plan for the creation of AEC, along with its four pillars, which are to: 1) realise a single market, 2) provide a highly competitive economic region, 3) ensure an equitable economic development process and 4) generate integration within and outside ASEAN economies. The proliferation of RTAs was also negotiated in the 2000s; for example, when ASEAN joined with: 1) China, Korea and Japan, 2) India and Malaysia, 3) India and Singapore and 4) ASEAN with India, Thailand and the US.

Evidence exists to show that the unilateral liberalisation taken in the late 1980s by the ASEAN-5 countries outside the ASEAN framework united ASEAN members in economic cooperation and contributed to increased intra-ASEAN trade flows (Imada, 1993; Ariff, 1994; Kettunen, 1998). The ASEAN-5 integration was possible partly due to regional economic cooperation initiated by the 5 nations, and partly due to anonymous market forces initiated by global policies. As of 2010 the ASEAN-5 countries eliminated tariffs on ASEAN-originated products on 99.65 per cent of tariff lines. The average CEPT tariff rate in the inclusion list reduced from 12.76 per cent in 1993 to 0.05 per cent in 2010. The average tariff rate among all ten ASEAN countries reduced from 4.43 per cent in 2000 to 1.06 per cent in 2010 (Sundram, 2011). Tariff reductions under the AFTA plan have contributed to the successful formation of a single market, but the integration effect for other ASEAN+ countries remains low. The ASEAN-5 region's per capita income in 2009 ranged from $\$ U S 1,790.00$ in the Philippines to \$US37,220.00 in Singapore (World Bank, 2010).

4 We focus on the founding members of ASEAN due to the availability of data. 
The SAARC was formed in 1985 by incorporating India, Pakistan, Bangladesh, Sri Lanka, Bhutan, Maldives and Nepal. In 1991 all seven member countries agreed to commit to integrate further under the umbrella of the South Asian Association for Regional Cooperation Preferential Trading Agreement (SAPTA), and in 1995, this became operational. The South Asian Free Trade Area (SAFTA) agreement came into effect in 2006. The unilateral liberalisation by a majority of member countries was negotiated in the 1990 s (non-discriminatory multilateralism), ${ }^{5}$ and more bilateral agreements between inside and outside member countries have been made since the 2000s. ${ }^{6}$ India, Pakistan and Sri Lanka agreed to reduce customs duties for products from those wealthy member countries to $0-5$ per cent by 2009 , to allow differential treatment for the least-developing members. India is the largest nation amongst them, contributing approximately 80 per cent of the regional GNI, and is the determining force in SAARC.

SAARC member countries experienced dissimilar policy experiences, even though they had similar historical and cultural links. The SAARC region's per capita income in 2009 was \$US1,087.00, and ranged from \$US440.00 in Nepal to \$US1,990.00 in Sri Lanka (World Bank, 2010). The SAARC region remains one of the poorest worldwide. It accounts for approximately 20 per cent of total world population, but generates less than two per cent of total world gross national product (computed from World Bank, 2010). Attempts at regional integration have also been unsatisfactory, because the region is disintegrating due to political differences, ethnic tensions, human rights abuses and corruption. The economic benefits of SAFTA were limited because the member countries cannot meet at summits due to political conflicts (Bandara and $\mathrm{Yu}, 2003$ ).

Countries that are well integrated can be subjected to macroeconomic fluctuations, such as business cycles, co-movement in subsets of countries, uncertainty in oil prices and increasing costs of international transportation. Income convergence/divergence can occur as a result of such global fluctuations. Kose (2002) emphasises that world price shocks play a significant role in driving business cycles and in co-movement properties of sectoral outputs in small, open, developing economies. Kose et al.

5 The extent of unilateral liberalisation across SAARC countries has not been consistent, and has varied over time; for example, Sri Lanka in 1977 and 1988, India in 1991 and 2001, Bangladesh in 1991 and Pakistan in 1996.

6 Agreements are as follows: 1) the India and Singapore Comprehensive Economic Cooperation Agreement in 2003, 2) India and Thailand in 2004, 3) India and Malaysia in a comprehensive economic partnership in 2004, 4) India and China in 2004, 5) India and Mercosur (Argentina, Brazil, Paraguay, Uruguay) in 2004, 6) India, Bolivia and Chile in 2004 and 7) ASEAN and India regional trade and investment area in 2003. 
(2003) argues that a common world factor is an important source of volatility for aggregates in most countries, providing evidence for world business cycles.

\section{Methodology}

This study used the time-series approach to examine conditional convergence by testing the stochastic convergence (equivalent to saying convergence in growth rate) and $\beta$ convergence (equivalent to saying convergence in level) of each of the sample countries, as proposed by Carlino and Mills (1993). Thus the present study accommodated both convergence in growth rate and then convergence in level. The convergence is actually non-divergence. We initially observe the performance of stochastic convergence, which is defined as shocks to the income of a given country relative to the average income across a set of countries (called 'relative income' hereafter) that will be temporary and does not diverge arbitrarily. This is then examined by using the unit-root test in a stationarity sense. Without stationarity, permanent deviation in any tendency toward convergence will occur when relative income shocks occur (Carlino and Mills, 1993).

Next, $\beta$ convergence means that a country with an initial income that is below the region's average grows faster than countries with initial incomes above the region's average. In other words, in the case of $\beta$ convergence, poor nations are catching up with rich nations. ${ }^{7}$ The conditional convergence concept identifies the causes that determine the membership of each 'club'. The existence of inequality may reflect limitations on financial development or protectionism (Baddeley, 2006). Many recent studies (Carlino and Mills, 1993; Bernard and Durlauf, 1995; Strazicich et al., 2004; Galvao Jr and Reis Gomes, 2007; Dawson and Sen, 2007) have used a time-series approach.

As mentioned above, stochastic convergence involves testing for a unit root in the log of a country's relative income. Stochastic convergence occurs when the income of a country, relative to the region's average, is stationary. A country $i$ 's relative income $\left(\mathrm{Y}_{i t}\right)$ is formulated as Equation 1; that is, the ratio of the annual series of a country's per capita real GNI divided by the average per capita real GNI of the region.

$y_{i t}=\ln \left[\mathrm{GNI}_{i t} /\left(\sum_{i=1}^{I} \mathrm{GNI}_{i t} / I\right)\right]$

where $I$ is the total number of nations.

7 An alternative measure is $\sigma$ convergence, which is based on an analysis of the evolution of a region's per capita income that relates a different group of countries, and 'shrinking differences', which indicates a strong convergence and can be identified as a 'convergence club'. 
In order to examine the stochastic convergence property of a nation's relative income, the first analysis begins with the ADF test. A rejection of the null of a unit root in the time series indicates stochastic convergence. However, the conventional ADF test is problematic, because it fails to consider the possible breaks in the univariate timeseries data. The conventional ADF test statistics may be biased towards the nonrejection of a unit root when the trend of a series was stationary within each of the sub-periods revealed by the breaks (Perron, 1997).

This present study adopted Lumpsdaine and Papell's approach (Lumpsdaine and Papell, 1997) using unit-root tests in the presence of two endogenously-determined structural breaks. The LP approach adapts a revised version of the ADF test, which is augmented by two endogenous breaks. The null hypothesis is the unit root against stationarity with two endogenously determined breaks as an alternative. We applied the LP model to the relative incomes of each of the sample countries and formed Equation 2 as follows:

$$
\Delta y_{i t}=\mu+\beta t+\theta D U 1_{t}+\gamma D T 1_{t}+\omega D U 2_{t}+\varphi D T 2_{t}+\alpha y_{t-1}+\sum_{l=1}^{k} c_{l} \Delta y_{t-l}+\varepsilon_{t}
$$

where $\Delta$ indicates the first difference operator, $y_{i t}$ is the time series of a nation $i$ 's relative income, $t=1, \ldots, T$, where $c(L)$ is a lag polynomial of known order $k$. This model includes sufficient numbers of lags $k$, to ensure that the residual term $\varepsilon_{t}$ is white noise, and the optimal lag length $k$ was selected based on the general-to-specific approach indicated by $\mathrm{Ng}$ and Perron (1995). $D U 1_{t}$ and $D U 2_{t}$ are dummy variables for a mean shift occurring at times $T B 1$ and TB2 $(1<T B<T$, where TB is the break date), respectively. $D T 1_{t}$ and $D T 2_{t}$ are the corresponding trend shift variables. $D U 1_{t}=$ 1 if $t>T B 1$ and zero otherwise; $D U 2_{t}=1$ if $t>T B 2$ and zero otherwise; $D T 1_{t}=t$ $T B 1$ if $t>T B 1$ and $D T 2_{t}=t-T B 2$ if $t>T B 2$ and zero otherwise. Two breaks will occur in both the intercept and slope term of the trend function. The break dates are confirmed depending on the minimum value of the $t$-statistics for $\alpha$. Using annual time series in this study (following Lumsdaine and Papell, 1997), we assumed that $k_{\max }$ is up to 8 . The decision rule is thus: if the $t$-statistic of $\alpha$ is higher than the five per cent critical value, then the unit root of null hypothesis cannot be rejected.

The evidence of stochastic convergence is a necessary, but not a sufficient condition for the notion of convergence; whereas the concept of $\beta$ convergence is considered essential because it indicates that a country with an initial income below the average grows faster than a country with an initial income above the average. In other words, 
if a poorer country's relative income is initially negative, then its growth rate should be positive and vice versa.

This section checks for $\beta$ convergence only in cases of stochastic convergence. This trend function model for $\beta$ convergence allowed this study to ascertain whether a nation was converging to the regional average over time. The basic $\beta$ convergence model is as follows:

$$
y_{i t}=\mu_{i}+\beta_{i} t+\varepsilon_{i t}
$$

where $y_{i t}$ is country $i$ 's relative income, $\mu$ represents the initial level of $y_{i t}$. The subscript $i(i=1,2,3)$ refers to the $i^{\text {th }}$ period, segmented by structural breaks, and the parameter $\beta$ indicates the average rate that a country's relative per capita income is converging to (or diverging from) the region's average. $t$ denotes a deterministic linear trend, and $\varepsilon_{i t}$ is a zero mean iid process. A given nation presents $\beta$ convergence if $\mu_{i}$ and $\beta_{i}$ are negatively related. In other words, $\beta$ convergence in a time-series approach requires initially poor nations (with a negative intercept) to grow at a rate faster than rich nations (shown by a positive trend-point estimate). This negative relation ( $\beta$ convergence) indicates a catching-up process in levels of per capita income. Therefore, the trend function test for $\beta$ convergence enables us to ascertain whether each individual nation is converging to the group's average income (that is, the average income of the founder members of ASEAN and SAARC countries respectively) over time.

Importantly, unlike the cross-sectional analysis, a time-series approach neither predicts the future path of relative per capita income levels nor estimates the speed-ofconvergence parameter. Any statistically significant value of $\beta_{i}$ in the linear trend specification (Equation 3) may imply either divergence or convergence during any time span in the future for an initially poor or rich nation. A country's relative income (which may currently be either positive or negative in value) is expected to converge to the regional average (representing zero value) with regional integration. $\beta$ convergence is an indicator that shows the extent of income convergence of the countries from their initial relative income. Sample countries may have a different number of structural breaks, and break dates also vary between countries; therefore, the convergence tendency and growth rate of per capita income are different. Equation 3 can include the intercept and slope dummy variables to capture the per capita income level and the corresponding growth rate of a nation's per capita income within the sub-periods, segmented by the structural breaks detected from the LP test, after 
which, the existence of $\beta$ convergence within the sub-period(s) of a nation can be examined. Equation 3 can be extended as follows:

$$
y_{i t}=\lambda_{0}+\lambda_{1} t+\lambda_{2} D U_{1 t}+\lambda_{3} D T_{1 t}+\lambda_{4} D U_{2 t}+\lambda_{5} D T_{2 t}+\varepsilon_{t}
$$

where $y_{i t}$ is once again country $i$ 's relative income. $D U_{1,2}$ is the intercept dummy for the break date of the univariate time series, and $\mathrm{DT}_{1,2}$ is the interactive term of the intercept and slope dummy. A summation of the estimated $\lambda_{m}(m=0,1,2,3,4,5)$ in Equation 4 can further refer to the performance of the $\beta$ convergence of each subperiod extended from the original model (Equation 4); that is: $\mu_{1}=\lambda_{0}, \mu_{2}=\lambda_{0}+\lambda_{2}$, $\mu_{3}=\lambda_{0}+\lambda_{2}+\lambda_{4}, \beta_{1}=\lambda_{1}, \beta_{2}=\lambda_{1}+\lambda_{3}$ and $\beta_{3}=\lambda_{1}+\lambda_{3}+\lambda_{5}$. For a case with only one break date we set $\lambda_{4}=\lambda_{5}=0$. If no break was identified, we then set $\lambda_{2}=\lambda_{3}=\lambda_{4}=\lambda_{5}=0$. Due to $\varepsilon_{t}$, it could be serially correlated, so the Newey-West (1987) approach was applied. All data used in this study were annual time-series data ranging from 1967-2005 for the ASEAN-5 countries, and the period 1973-2005 for the SAARC-5 countries. ${ }^{8}$

\section{Empirical results}

This study began with the ADF and LP tests to find the stochastic convergence of the ASEAN-5 and SAARC countries. Based on the results of the ADF tests, the LGNI for Malaysia was trend stationary, and $I(0)$, and the remaining variables were stationary after the first difference, I(1). Summing up the LP two-break test results, this study identified two significant breaks for many countries, and one break each for Malaysia and the Philippines. The two-break unit-root null can be rejected at the five per cent significance level for all the ASEAN-5 sample countries, which implies that all ASEAN-5 sample countries showed stochastic convergence. The time-series tests for stochastic convergence were then supplemented with tests which show evidence for the notion of a $\beta$ convergence model. ${ }^{9}$

The first structural break for each of Indonesia, Singapore and Thailand occurred in 1979, 1983 and 1981 respectively. The breaks show a downward trend that coincides with the world oil crisis. The second structural break for all the member countries of ASEAN occurred in 1997 (except Thailand), which coincided with the Asian crisis (see Table 1 and Figure 1). The 1988 break for Thailand tends to show an upper trend, and this coincided with stabilisation policies directly after the severe recession that

8 The data for Bangladesh was available since its independence in 1971, which has restricted our analysis on SAARC countries since 1973.

${ }^{9}$ See Jayanthakumaran and Lee (2011) and Jayanthakumaran and Lee (2009). 
occurred due to the steady fall in the price of oil. SAARC-5 sample countries were not stochastically convergent.

Table 1: Results of stochastic convergence: ASAEN-5 and SAARC-5 countries

\begin{tabular}{|c|c|c|c|c|c|c|}
\hline \multicolumn{7}{|l|}{ Unit root test } \\
\hline \multirow{2}{*}{\begin{tabular}{|l|} 
Test \\
Country's relative \\
GNI (in log)
\end{tabular}} & \multirow{2}{*}{\begin{tabular}{|l|} 
ADF test \\
Test stat. \\
\end{tabular}} & \multicolumn{5}{|c|}{ Two-break LP test } \\
\hline & & $k$ & TB1 & TB2 & Test sta & Inference \\
\hline \multicolumn{7}{|l|}{ ASEAN-5 } \\
\hline Indonesia & $-2.08(1)$ & 1 & 1979 & 1997 & $-6.98 *$ & stationary/stochastic convergence \\
\hline Malaysia & $-4.70 *(1)$ & 1 & $1990 n$ & 1997 & $-9.91 *$ & stationary/stochastic convergence \\
\hline Philippines & $-2.04(1)$ & 1 & $1985 n$ & 1997 & $-7.63 *$ & stationary/stochastic convergence \\
\hline Singapore & $-0.87(2)$ & 2 & 1983 & 1997 & $-7.18^{*}$ & stationary/stochastic convergence \\
\hline Thailand & $-2.44(4)$ & 1 & 1981 & 1988 & $-7.56^{*}$ & stationary/stochastic convergence \\
\hline \multicolumn{7}{|l|}{ SAARC-5 } \\
\hline Bangladesh & $-2.10(1)$ & 8 & 1986 & 2002 & -6.55 & unit root \\
\hline India & $-1.98(1)$ & 2 & 1989 & 2000 & -6.02 & unit root \\
\hline Nepal & $-0.39(1)$ & 8 & 1987 & 2001 & -6.12 & unit root \\
\hline Pakistan & $-1.24(1)$ & 2 & 1981 & 1989 & -5.96 & unit root \\
\hline Sri Lanka & $-1.78(1)$ & 8 & 1994 & 1998 & -6.06 & unit root \\
\hline
\end{tabular}

Notes: * denotes 5\% significance level. For the ADF test, the number in parentheses is the order of augmentation determined by Akaike's information criterion (AIC). Critical values are computed based on Mackinnon (1996). For the Lumsdaine and Papell test, the critical value at the $5 \%$ level of significance is $-6.82 . k$ is lag length. $\mathbf{n}$ denotes that the break is statistically insignificant. TB1 and TB2 represent the first and the second structural break, respectively. 
Figure 1: Plots of each of ASEAN-5 and SAARC-5 countries series and endogenously estimated timing of structural breaks by the LP tests

\section{ASEAN-5 countries}
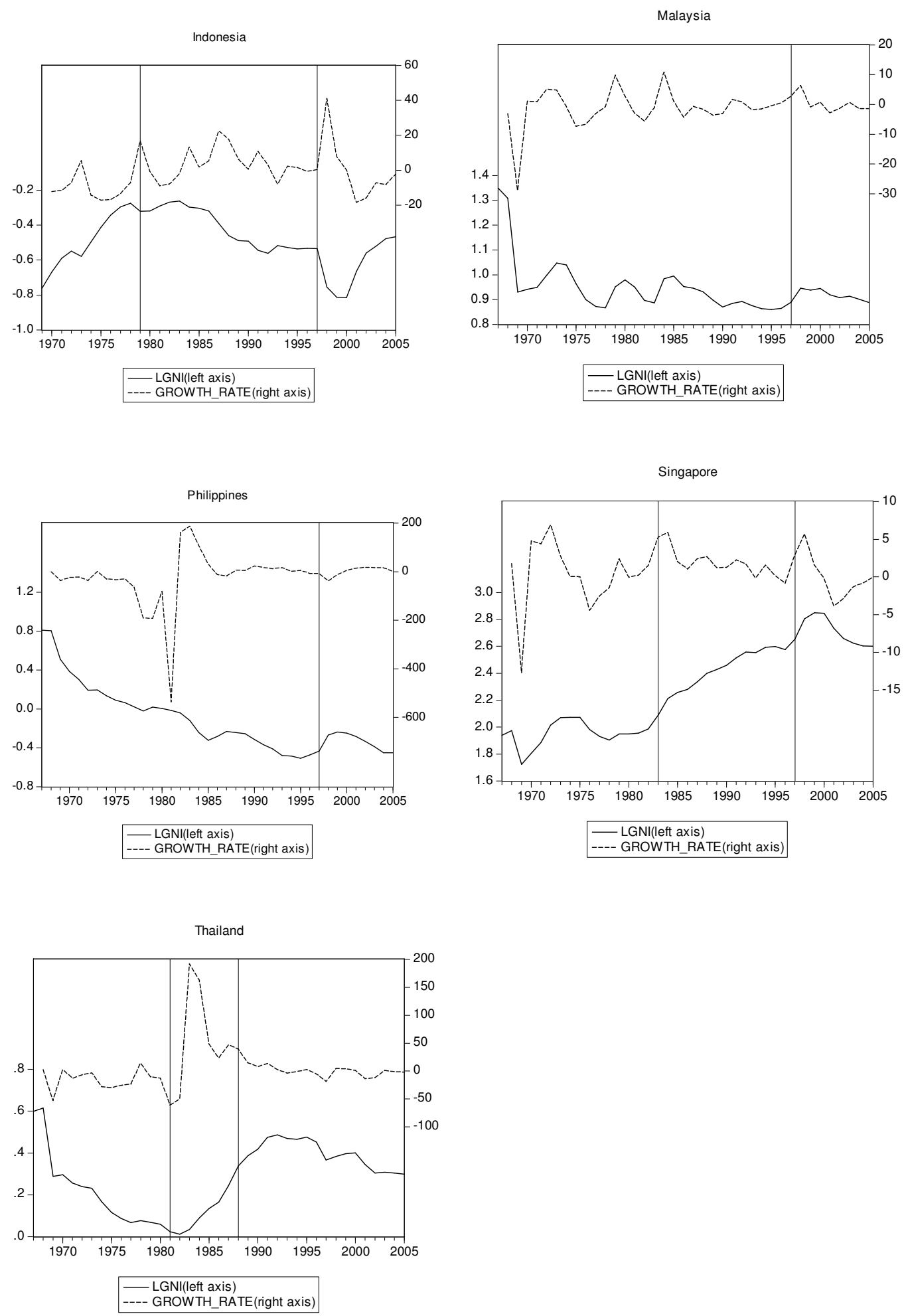

Figure 1 (continued) 


\section{SAARC-5 countries}
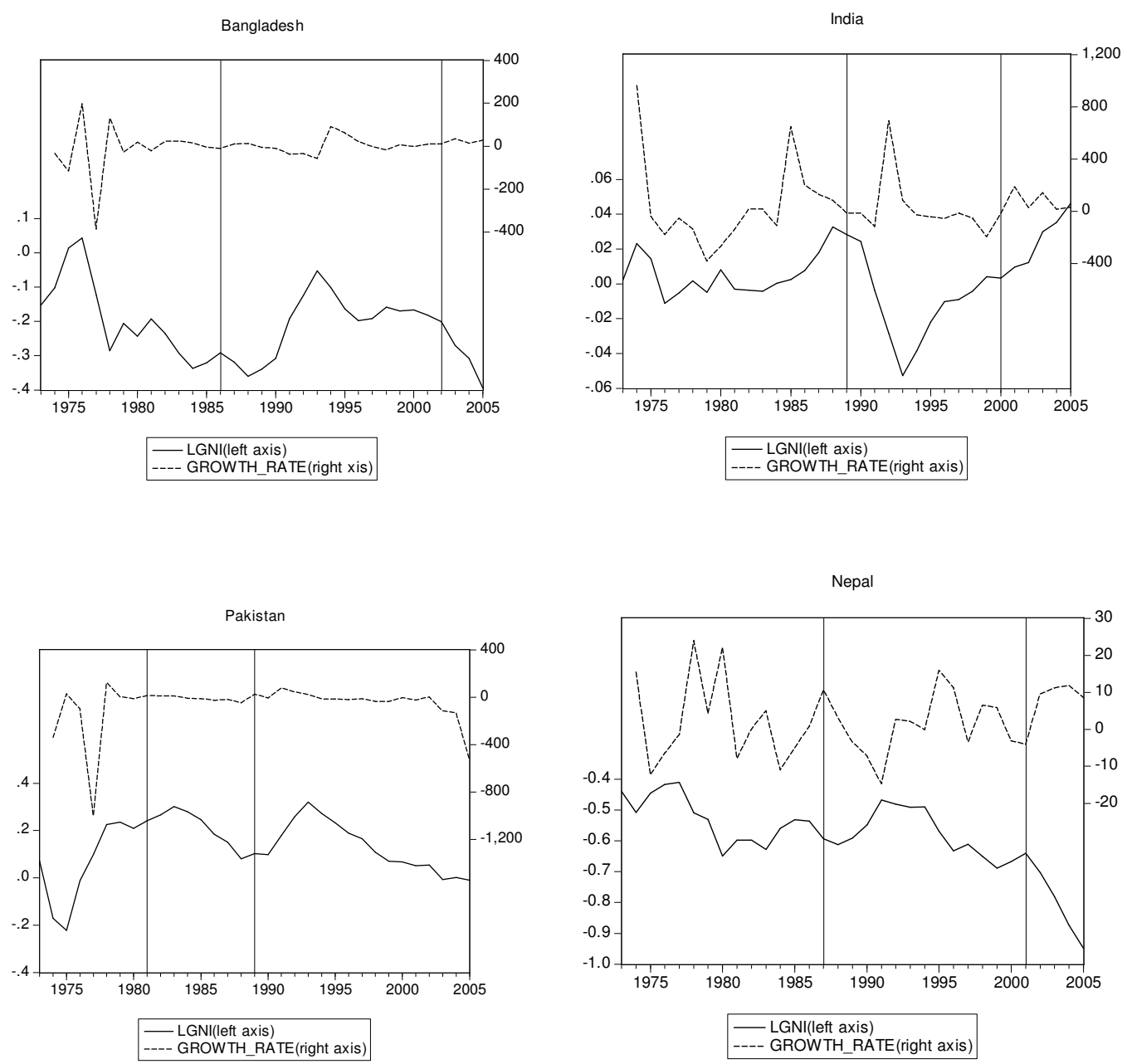

Sri Lanka

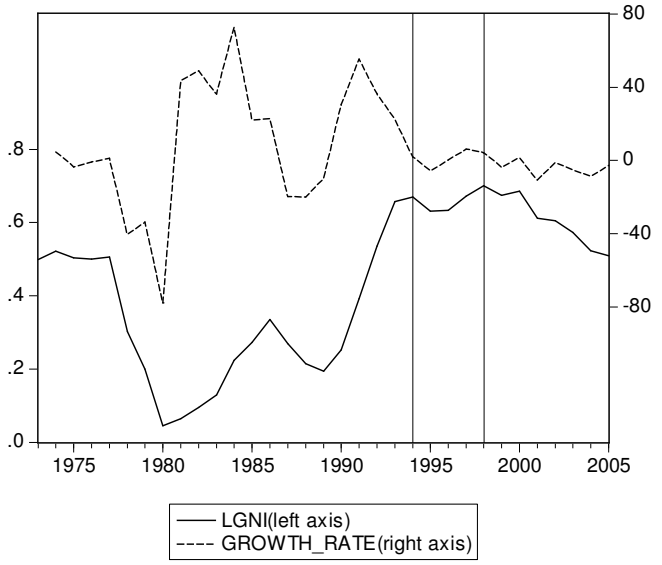

The $\beta$ convergence tests were applied to the ASEAN-5 sample countries and showed a stochastic convergence obtained from the previous estimation. The results of the $\beta$ convergence tests are shown in Table 2 . Here, $\mu 1$ is the estimate of the per capita 
income level in the first year of the study period (1967), and $\beta 1$ is an estimate of per capita income growth rate during the pre-break period (for Thailand during the 19671980 period). $\beta 2$ and $\beta 3$ represent per capita income growth rate for the remaining break periods (for Thailand: 1981-87 and 1988-2005). If we combine the results of $\mu 1$ and $\beta 1$, and the criterion for convergence, and they are inversely related in all states except Singapore where Indonesia's initial relative income was below the regional average and caught up at 6.54 per cent above the regional average.

The per capita income levels ( $\mu 1$ and $\mu 2)$ and per capita income growth rates ( $\beta 1$ and $\beta 2$ ) for Malaysia and the Philippines remain unchanged. For Malaysia, $\beta$ convergence occurs throughout the whole sample period (1967-2005). Throughout the study period, Malaysia's per capita income was 99.12 per cent above the regional average in 1967 , but this nation had an annual growth rate that was 0.39 per cent below the regional average in 1967-2005. Similarly, the $\beta$ convergence for the Philippines occurred from 1967 to 2005 . The initial relative income was 23.89 per cent above the regional average in 1967, but the annual growth rate was approximately 2.40 per cent below the regional average throughout the period of investigation. The $\beta$ convergence results for Malaysia and the Philippines suggest that both countries are downwardly converging in per capita income to the regional average over time. For Singapore, $\beta$ convergence occurred during 1997-2005. The initial level of per capita income was 312.48 per cent above the regional average in 1997, but the nation had an annual growth rate that was 1.37 per cent below the regional average during 1997-2005. The result of $\mu 3$ is consistent with the fact that Singapore was the richest state in ASEAN, and its per capita income was higher than other states.

For Thailand, $\beta$ convergence occurred from 1967. During 1967-1980, we see that Thailand's per capita income was 36.01 per cent above the regional average in 1967 , but the nation had an annual growth rate that was 2.64 per cent below the regional average during 1967-1980. From 1981 to 1987, Thailand's per capita income was 70.24 per cent below the regional average in 1981, with an annual growth rate of 4.87 per cent above the regional average in 1981-87. From 1988 to 2005, Thailand's per capita income was 54.38 per cent above the regional average in 1988, but the nation had an annual growth rate of 0.55 per cent below the regional average during 19882005.

For Indonesia, $\beta$ convergence occurred from 1967. During 1967-79, the initial relative income was 79.75 per cent below the regional average in 1967, but Indonesia had an annual growth rate of 6.54 per cent above the regional average throughout this 
period. From 1980 to 1997 , the initial relative income was 23 per cent above the regional average in 1980, with an annual growth rate of 43 per cent below the regional average during this period. There was no convergence during 1997-2005.

This study tested for conditional convergence by examining the stochastic convergence and $\beta$ convergence. The results showed that all the ASEAN-5 sample countries were stochastically convergent, but not the SAARC-5 sample countries. This study further found that $\beta$ convergence exists for Malaysia, the Philippines, Singapore, Indonesia and Thailand.

Table 2: Results of $\beta$-convergence

\begin{tabular}{|c|c|c|c|c|c|c|c|c|c|}
\hline \multicolumn{10}{|c|}{ Beta convergence } \\
\hline \multicolumn{7}{|c|}{ Intercept and trends } & \multicolumn{3}{|c|}{ Beta convergence } \\
\hline Country & $\mu 1$ & $\beta 1$ & $\mu 2$ & $\beta 2$ & $\mu 3$ & $\beta 3$ & 1 & 2 & 3 \\
\hline \multicolumn{10}{|l|}{ ASEAN-5 } \\
\hline Indonesia & -0.7975 & 0.0654 & 0.0230 & -0.0249 & -0.4330 & -0.0047 & yes & yes & no \\
\hline Malaysia & 0.9912 & -0.0039 & 0.9912 & -0.0039 & & & yes & yes & no \\
\hline Philippines & 0.2389 & -0.0240 & 0.2389 & -0.0240 & & & yes & yes & no \\
\hline Singapore & 1.9745 & & 1.4014 & 0.0439 & 3.1248 & -0.0137 & no & no & yes \\
\hline Thailand & 0.3601 & -0.0264 & -0.7024 & 0.0487 & 0.5438 & -0.0055 & yes & yes & yes \\
\hline
\end{tabular}

Notes: Based on the basic trend function Equation 4, and the two-break trend function Equation 5, we see that $\mu_{1}=\lambda_{0}, \mu_{2}=\lambda_{0}+\lambda_{2}, \mu_{3}=\lambda_{0}+\lambda_{2}+\lambda_{4}, \beta_{1}=\lambda_{1}, \beta_{2}=\lambda_{1}+\lambda_{3}$ and $\beta_{3}=\lambda_{1}+\lambda_{3}+\lambda_{5}$. For the case with only one-break date, including Malaysia and the Philippines, we set $\lambda_{4}=\lambda_{5}=0$. For Singapore, this study cannot reject $\beta 1\left(\lambda_{1}\right)$, which is statistically zero. Serial correlation is corrected by using the Newey-West (1987) approach.

\section{Conclusions}

This paper investigated the time-series evidence on the convergence of relative per capita incomes in a two entirely different RTA original member countries: ASEAN-5 and SAARC-5. Rejection of the unit-root null hypothesis in the relative per capita income series for a country constitutes evidence in favour of stochastic convergence. Therefore, the evidence for the stochastic convergence for all the ASEAN member countries, with significant trend breaks, has been established. Breaks for the majority of ASEAN member countries coincided with the world oil crisis (1980s) and the Asian crisis (1997). Thailand's second trend break occurred in 1988 and coincided with Thailand's stabilisation policies in the mid-1980s. No evidence was found of stochastic convergence for all the SAARC-5 countries, probably because they 
remained the least integrated inside and outside the region; while among the SAARC countries, India's size is not proportional to her neighbours'.

We might have expected to see the 'opposite signs' condition of $\beta$ convergence on the estimated intercept and slope coefficients in the case of absolute convergence (Carlino and Mills, 1993). The results showed that all the ASEAN-5 countries were stochastically convergent and can be tested for $\beta$ convergence. We found evidence of $\beta$ convergence for Malaysia, Indonesia and the Philippines before the Asian crisis, but they have diverged since then. Thailand consistently converged from 1967 to 2005 . Singapore began converging after the Asian crisis. Importantly, structural breaks associated with the world oil crisis and the Asian crisis heavily influenced the convergence/divergence process. Structural breaks are not especially associated with the changes to trade policy and economic integration. Our tests were only concerned with two breaks in the series, and could not detect multiple structural breaks that may have occurred during the period concerned. A better methodology is needed to capture the relationship between trade integration and per capita income.

The limitations of the unit-root test are due to its low power in rejecting the null hypotheses on I(1), particularly when there were relatively few degrees of freedom. These findings are specific to the ASEAN-5 and SAARC-5 settings, so the general limitations on a focused case study research still apply. 


\section{References}

Ariff, M. (1994) Open regionalism a la ASEAN, Journal of Asian Economics, 5(1): 99-117.

Baddeley, M. (2006) Convergence or divergence? The impacts of globalisation on growth and inequality in less-developed countries, International Review of Applied Economics, 20(3): 391-410.

Bandara, J.S. and Yu, W. (2003) How Desirable is the South Asian Free Trade Area? A quantitative economic assessment, The World Economy, 26(9): 1293-1323.

Barro, R.J. and Sala-i-Martin, X. (1992), Convergence, Journal of Political Economy, 100(2): 223-251.

Ben-David, D. (1996) Trade and convergence among countries, Journal of International Economics, 40(3/4): 279-298.

Bernard, A.B. and Durlauf, S.N. (1995) Convergence in International Output, Journal of Applied Econometrics, 10(2): 97-108.

Carlino, G. and Mills, L. (1993) Are US regional economies converging? A time series analysis, Journal of Monetary Economics, 32(2): 335-346.

Choi, C. (2009) Does bilateral trade lead to income convergence? Panel evidence, Journal of Economic Development, 34(1): 71-79.

Dawson, J.W. and Sen, A. (2007) New evidence on the convergence of international income from a group of 29 countries, Empirical Economics, 33(2): 199-230.

Fung, M.K.Y. and Chow, C.K.W. (2011) Note on the productivity convergence of airports in China, Pacific Economic Review, 16(1): 120-133.

Freund, C. (2000) Multilateralism and the endogenous formation of preferential trade agreements, Journal of International Economics, 52(2): 359-376.

Friedman, M. (1992) 'Do old fallacies ever die?', Journal of Economic Literature, 30(4): 2129-2132.

Galvao A.F. Jr and Reis Gomes, F.A. (2007) Convergence or divergence in Latin America? A time series analysis, Applied Economics, 39(11): 1353-1360.

Ghose, A.K. (2004) Global inequality and international trade, Cambridge Journal of Economics, 28(2): 229-252.

Imada, P. (1993) Production and trade effects of an ASEAN Free Trade Area, The Developing Economies, 31(1): 3-23.

Jayanthakumaran, K. and Lee, Shao-Wei. (2011) What lessons can be learned for SAARC from ASEAN?, International Journal of Social and Economic Research, 1 (1), 120-147.

Jayanthakumaran, K. and Lee, Shao-Wei. (2009) Multilateralism, regionalism and income convergence: ASEAN and SAARC In Jayanthakumaran, K. (2009), (ed.) Advanced Technologies, Croatia: In-Teh. 
Kettunen, E. (1998) Economic integration of the ASEAN countries. In Grunsven, L.V. (ed.) Regional Change in Industrialising Asia. Sydney: Ashgate.

Kose, M. Ayhan. (2002) Explaining business cycles in small open economies: How much does world price matter?, Journal of International Economics, 56(2): 299-327.

Kose, M. Ayhan, Otrok, C. and Whiteman, C.H. (2003) International business cycles: world, region and country-specific factors, American Economic Review, 93(4): 1216-1239.

Leung, C.K.Y. and Quah, D.T. (1996) Convergence, endogenous growth and productivity disturbances, Journal of Monetary Economics, 38(3): 535-547.

Li, H. and Xu, Z. (2007) Economic convergence in seven Asian economies, Review of Development Economics, 11(3): 531-549.

Linden, M. (2000) Testing growth convergence with time series data - a nonparametric approach, International Review of Applied Economics, 14(3): 361370.

Lumsdaine, R.L. and Papell, D.H. (1997) Multiple trend breaks and the unit-root hypothesis, The Review of Economics and Statistics, 79(2): 212-218.

Mackinnon, J.G. (1996) Numerical distribution functions for unit root and cointegration tests, Journal of Applied Econometrics, 11(6): 601-618.

Moon, W. (2006) Income convergence across nations and regions in East Asia, Journal of International and Area Studies, 13(2): 1-16.

Newey, W.K. and West, K.D. (1987) A simple, positive seme-definite, heteroskedasticity and autocorrelation consistent covariance matrix, Econometrica, 55(3): 703-708.

Ng, S. and Perron, P. (1995) Unit Root tests in ARMA models with data-dependent methods for the selection of the truncation lag, Journal of American Statisstical Association 90: 268-81.

Niebuhr, A. and Schlitte, F. (2004) Convergence, trade and factor mobility in the European Union - implications for enlargement and regional policy, Intereconomics, 39(3): 167-177.

Oh, K-Y. and Evans, P. (2011) Test of the convergence hypothesis allowing for crosssectional dependence, Pacific Economic Review, 16(3): 302-312.

Perron, P. (1997) Further evidence on breaking trend functions in macroeconomic variables, Journal of Econometrics, 80(2): 355-385.

Quah, D.T. (1996) Twin peaks: growth and convergence in models of distribution dynamics, Economic Journal, 106(437): 1045-1055.

Romer, P.M. (1994) The origins of endogenous growth, Journal of Economic Perspectives, 8(1): 3-22. 
Silvestriadou, K. and Balasubramanyam, V.N. (2000) Trade policy, foreign direct investment and convergence, Review of Development Economics, 4(3): 279291.

Slaughter, M.J. (1997) Per-capita convergence and the role of international trade, The American Economic Review, 87(2): 194-199.

Strazicich, M.C, Lee, J.S. and Day, E. (2004) Are incomes converging among OECD countries? Time series evidence with two structural breaks, Journal of Macroeconomics, 26: 131-145.

Sundram, P. (2011), ASEAN Economic Community Blueprint and Roadmap. Paper presented in the Workshop on the Emerging Asia 2030: Challenges Ahead, 2425 January 2011, Tokyo, Japan.

Wagle, U.R. (2007) Are economic liberalisation and equality compatible? Evidence from South Asia, World Development, 35(11): 1836-1857.

World Bank (2010) World Development Indicators Database, Washington, DC. 